\title{
PERBANDINGAN EFEKTIFITAS METODE RESOURCE BASED LEARNING DENGAN METODE DISKUSI TERHADAP HASIL BELAJAR BIOLOGI
}

\author{
NETTY DEMAK H. SITANGGANG \\ nettybiologi@gmail.com \\ Program Studi Pendidikan Biologi, Fakultas Teknik, Matematika dan IPA \\ Universitas Indraprasta PGRI
}

\begin{abstract}
Abstrak. Metode penelitian yang digunakan untuk menganalisis adalah metode eksperimen, sedangkan pengujian hipotesis menggunakan Uji-t untuk uji beda rata-rata, yang sebelumnya telah dilakukan uji normalitas menggunakan uji Liliefors dan uji homogenitas menggunakan uji Fisher. Berdasarkan uji normalitas data kelas eksperimen dengan menggunakan rumus uji Liliefors didapat Lo $<$ Ltabel $(0.08<0.19)$, sedangkan kelas kontrol Lo $<$ Ltabel $(0.109<0.19)$, dari data tersebut dapat dinyatakan kedua kelas berdistribusi normal, sedangkan untuk uji homogenitas didapat Fhitung < Ftabel $(1.13<$ 2.165) adalah homogen. Berdasarkan dari uji hipotesis untuk beda rata-rata kelas yang dilakukan dengan menggunakan uji-t maka didapatkan hasil Thitung > Ttabel (4.647 > 2.093), maka hipotesis $H_{0}$ di tolak dan $H_{l}$ diterima.Hasil temuan penelitian dapat disimpulkan bahwa hasil belajar Biologi yang dilakukan dengan menggunakan metode Resource Based Learning untuk materi Ekosistem yang diajarkan terdapat perbedaan dengan menggunakan metode Diskusi pada matapelajaran Biologi materi Ekosistem kelas X MA Al-Khairiyah.
\end{abstract}

Kata Kunci: metode resource based learning, metode diskusi, hasil belajar

\begin{abstract}
Research methods used to analyze the experimental method, whereas hypothesis testing using t-test for mean difference test, which had previously been carried out using test Liliefors normality test and homogeneity test using Fisher's exact test. Based on experimental data normality test class using test formula obtained Liliefors Lo $<$ Ltable $(0: 08<0.19)$, while the control class Lo < Ltable $(0.109<0.19)$, of the data can be expressed both classes are normally distributed, whereas the $F$ value obtained for test of homogeneity < Ftable $(1.13<2.165)$ is homogeneous. Based on the hypothesis test for the difference of the average grade is performed using the t-test showed tcount $>$ ttable $(4,647>2,093)$, then the hypothesis $\mathrm{H} 0$ is rejected and $\mathrm{H} 1$ is accepted. The findings of this study concluded that the results of a study conducted by the Biological Resource Based Learning method for the material being taught Ecosystem differences with discussion on lesson using materials Ecosystems Biology class X MA Al-Khairiyah.
\end{abstract}

Keywords: resource-based learning method, the method of discussion, learning outcomes

\section{PENDAHULUAN}

Di Indonesia, sistem pendidikan semakin berkembang diiringi dengan kemajuan teknologi dan tingkat daya berpikir manusia yang semakin intelektual. Namun, kualitas pendidikan masih sangat kurang dan sangat jauh dari standar kualitas pengajaran. Hal tersebut dikarenakan kurangnya keterampilan dan kinerja yang dimiliki guru, seringkali guru juga malas untuk menggunakan metode yang bervariasi sehingga proses belajar mengajar menjadi sangat monoton. 
Siti Hasanah (2005: 1-2) menyatakan sebagai berikut.

"Belajar bukan hanya suatu proses untuk mentransfer ilmu yang berasal dari buku panduan pelajaran, tetapi juga wawasan dari para pengajar. Karena belajar bukan hanya untuk mendapatkan pengetahuan, seperti yang telah Benjamin Bloom klasifikasikan dalam Taksonomi Bloom bahwa dalam proses belajar mengajar, siswa harus mendapatkan enam tujuan pembelajaran ranah kognitif, yaitu pengetahuan (knowledge), pemahaman (comprehention), penerapan (application), analisis (analysis), sintesis, dan evaluasi. Keenam tujuan tersebut dapat mencapai evaluasi hasil belajar secara optimal."

Hasil belajar dapat tercapai dengan optimal, bukan hanya dari pemahaman siswa dan wawasan guru yang luas, tetapi juga dari pendukung proses belajar yang lain, seperti silabus, RPP, bahan ajar, metode pelajaran, media pelajaran, dan evaluasi. Untuk lebih mengoptimalkan hasil belajar dan mengaktifkan interaksi antar guru dan siswa, dibutuhkan metode yang mendukung suatu pelajaran agar menaikkan tingkat keberhasilan hasil belajar siswa.

Ada banyak sekali metode pembelajaran, diantaranya adalah metode diskusi, curah pendapat, ceramah, demonstrasi, pemecahan masalah (problem solving), resource based learning, kooperatif, dan sebagainya. Metode tersebut dapat digunakan pada semua pengajaran, khususnya dalam materi Ekosistem, dimana siswa memerlukan suatu aplikasi agar lebih mudah memahami materi tersebut.

Pada penelitian ini, peneliti menggunakan metode resource based learning dan metode diskusi sebagai perbandingannya. Hal tersebut dikarenakan sekolah yang menjadi tempat penelitian ini belum menggunakan metode resource based learning. Sekolah tersebut hanya menggunakan metode ceramah, tanya jawab, dan diskusi. Oleh karena itu, peneliti juga menggunakan metode diskusi yang telah diterapkan sekolah untuk menjadi pembanding dalam hasil belajar terhadap metode resource based learning.

Dengan penjabaran umum kedua metode tersebut, dapat diperjelas kembali, bahwa metode resource based learning mempunyai sumber beraneka ragam untuk memperdalam suatu materi. Hal tersebut tidak diharuskan dengan sesuatu yang formal dan bersifat buku, tetapi bisa didapati dari lingkungan sekitar, sedangkan metode diskusi mempunyai ruang debat yang sangat jelas dan nyata dalam hal mengungkapkan persepsi siswa masing-masing. Akan tetapi, metode diskusi ini sangat terbatas dalam hal sumbernya, sehingga metode tersebut lebih mengandalkan pola pikir dan wawasan yang sudah ada.

Kedua metode tersebut kemudian diterapkan dalam mata pelajaran Biologi materi Ekosistem. Dalam materi ekosistem ini diperlukan wawasan dan tingkat penalaran yang cukup tinggi dalam mengelompokkan ekosistem-ekosistem yang ada pada biosfer. Dengan demikian, penelitian ini dilakukan untuk mengetahui tingkat perbedaan hasil belajar siswa, dengan keefektifan metode Resource Based Learning (RBL) ataupun dengan metode Diskusi pada mata pelajaran Biologi materi Ekosistem, dan penelitian ini diterapkan pada siswa kelas X di Madrasah Aliyah (MA) Al-Khairiyah.

\section{TINJAUAN PUSTAKA}

Dalam dunia pengajaran banyak sekali metode pembelajaran yang diterapkan oleh guru untuk membantu dalam memberikan materi kepada siswa. Akan tetapi guru seringkali kurang tepat dalam menggunakan metode pembelajaran tersebut, sehingga membuat proses belajar mengajar menjadi terganggu.

Dari sekian banyak variasi metode pembelajaran diantaranya adalah metode resource based learning dan metode diskusi. Kedua metode tersebut dijadikan perlakuan 
kepada siswa untuk menguji perbedaan diantara keduanya dan mengetahui ketepatan dalam penggunaan metode untuk suatu materi pembelajaran. Metode resource based learning dan metode diskusi dipilih karena mempunyai ciri khas masing-masing. Metode resource based learning mempunyai ciri utama yaitu gaya belajar yang bebas dan sumber belajar yang tak terbatas, sedangkan metode diskusi mempunyai ciri khas dalam memberikan pendapat untuk mempertahankan argumen-argumen kelompok.

Metode-metode tersebut diterapkan kepada siswa pada mata pelajaran biologi materi ekosistem kelas X MA Al-Khairiyah dan juga sebagai variabel bebas dalam penelitian ini. Sekolah ini mempunyai kelas X, kelas X-1 yang dijadikan kelas kontrol dengan menggunakan metode diskusi, sedangkan kelas X-2 dijadikan kelas eksperimen dengan menggunakan metode resource based learning.

Setelah kedua metode tersebut diterapkan pada masing-masing kelas penelitian, siswa akan diberikan instrumen soal pilihan ganda untuk mengetahui tingkat hasil belajar siswa dalam memahami pelajaran. Hasil belajar tersebut dijadikan variabel terikat karena menjadi tujuan akhir dalam penelitian. Sebelum instrumen diberikan kepada kelas penelitian, instrumen tersebut diuji coba dahulu di kelas XI IPA untuk mengetahui tingkat kevalidan soal.

Soal-soal yang telah valid dan reliabel akan diujikan pada kelas penelitian, yang hasil belajarnya dari tiap kelas akan dibandingkan dengan pengolahan data kuantitatif. Dalam penelitian ini diharapkan, metode resource based learning dapat memberikan hasil belajar yang sangat baik dibandingkan hasil belajar belajar dengan metode diskusi dan dapat membantu siswa serta guru dalam memperlancar proses belajar mengajar.

\section{METODE}

Perlakuan terhadap subjek dalam penelitian ini berupa penggunaan metode pembelajaran. Metode pembelajaran yang dimaksud adalah metode pembelajaran resource based learning dan diskusi. Perlakuan ini diberikan selama 4x pertemuan dalam pemberian materi Ekosistem dan pemberian instrumen pengukuran hasil belajar materi Ekosistem.

Pada metode pembelajaran resource based learning, siswa diberikan kebebasan untuk memilih sendiri ataupun menggunakan apa saja sebagai sumber belajarnya, sedangkan pada metode pembelajaran diskusi, siswa tidak diberi kebebasan, tetapi diberikan sub-sub materi untuk dijadikan bahan diskusi dengan membentuk kelompok. Pengukuran kemampuan pemecahan masalah Ekosistem dalam mata pelajaran Biologi dilakukan sesudah proses perlakuan eksperimen selesai dilaksanakan. Pertemuan tatap muka yang dilakukan selama perlakuan mengikuti jadwal yang telah disusun sebelumnya.

\section{HASIL DAN PEMBAHASAN}

Pada penelitian ini, siswa yang telah diberi perlakuan akan diambil hasil belajarnya dengan instrumen penelitian, yang mana instrumen tersebut telah melalui proses validasi soal dari 35 butir menjadi 28 butir soal yang valid, dari masing-masing skor tiap butir adalah 1. Jadi skor maksimum dalam penelitian ini adalah 28.

\section{Skor Hasil Belajar Siswa Kelas Eksperimen}

Secara keseluruhan, skor yang diperoleh dari sampel hasil belajar siswa kelas X-2 kelas eksperimen dengan skor tertinggi 22 dan skor terendah 14, jumlah rata-rata nilai 18.1, median 18.2, modus 18.5, dan simpangan baku berjumlah 2.5. 
Tabel 1. Daftar Distribusi Kelas Eksperimen

\begin{tabular}{|c|c|c|c|c|c|c|c|c|c|c|c|}
\hline \multicolumn{2}{|c|}{$\begin{array}{c}\text { KELAS } \\
\text { INTERVAL }\end{array}$} & fi & $f r$ & $F p$ & $f k \%$ & $x i$ & fi.xi & $(x i-\underline{x})^{2}$ & $f i .(x i-\underline{x})^{2}$ & $\begin{array}{c}\text { TEPI } \\
\text { BAWAH } \\
\end{array}$ & $F$ \\
\hline 14 & 15 & 3 & 0.15 & 15 & 15 & 14.5 & 43.5 & 12.96 & 38.88 & 13.5 & 3 \\
\hline 16 & 17 & 5 & 0.25 & 25 & 40 & 16.5 & 82.5 & 2.56 & 12.8 & 15.5 & 8 \\
\hline 18 & 19 & 6 & 0.3 & 30 & 70 & 18.5 & 111 & 0.16 & 0.96 & 17.5 & 14 \\
\hline 20 & 21 & 5 & 0.25 & 25 & 95 & 20.5 & 102.5 & 5.76 & 28.8 & 19.5 & 19 \\
\hline 22 & 23 & 1 & 0.05 & 5 & 100 & 22.5 & 22.5 & 19.36 & 19.36 & 21.5 & 20 \\
\hline \multicolumn{2}{|c|}{$\Sigma$} & 20 & 1 & 100 & & & 362 & & 100.8 & & \\
\hline
\end{tabular}

\section{Skor Hasil Belajar Siswa Kelas Kontrol}

Secara keseluruhan skor yang diperoleh dari data sampel hasil belajar siswa kelas X-1 kelas kontrol dengan skor tertinggi 19 dan skor terendah 11. Pada data sampel ini juga diperoleh rata-rata skor 15.8, median 16.1, modus 17, dan simpangan baku 2.6.

Tabel 2. Daftar Distribusi Kelas Kontrol

\begin{tabular}{|c|c|c|c|c|c|c|c|c|c|c|c|}
\hline \multicolumn{2}{|c|}{ KELAS } & $f i$ & $f r$ & $f p$ & $f k \%$ & $x i$ & $f i . x i$ & $(x i-\underline{x})^{2}$ & $f i .(x i-\underline{x})^{2}$ & $\begin{array}{c}\text { TEPI } \\
\text { BAWAH }\end{array}$ & $F$ \\
\hline 11 & 12 & 3 & 0.15 & 15 & 15 & 11.5 & 34.5 & 18.49 & 55.47 & 10.5 & 3 \\
\hline 13 & 14 & 3 & 0.15 & 15 & 30 & 13.5 & 40.5 & 5.29 & 15.87 & 12.5 & 6 \\
\hline 15 & 16 & 5 & 0.25 & 25 & 55 & 15.5 & 77.5 & 0.09 & 0.45 & 14.5 & 11 \\
\hline 17 & 18 & 6 & 0.3 & 30 & 85 & 17.5 & 105 & 2.89 & 17.34 & 16.5 & 17 \\
\hline 19 & 20 & 3 & 0.15 & 15 & 100 & 19.5 & 58.5 & 13.69 & 41.07 & 18.5 & 20 \\
\hline \multicolumn{2}{|c|}{$\Sigma$} & 20 & 1 & 100 & & & 316 & & 130.2 & & \\
\hline
\end{tabular}

\section{Uji Normalitas}

Untuk mengetahui apakah data yang diperoleh berasal dari populasi berdistribusi normal atau tidak, akan dilakukan uji normalitas dengan menggunakan uji Liliefors. Kriteria pengujian normalitas adalah terima $H_{0}$ jika Lo kurang dari Ltabel atau diterima jika $H_{l}$ jika $L o$ lebih dari Ltabel. Dengan diterimanya $H_{0}$ maka dalam data penelitian berasal dari populasi berdistribusi normal.

Tabel 3. Uji Normalitas Kelas eksperimen

\begin{tabular}{|c|c|c|c|c|c|c|c|c|}
\hline SKOR $(x i)$ & $f i$ & $f k$ & $z i$ & NILAI TABEL & $f(z i)$ & $S(z i)$ & $f(z i)-S(z i)$ & $\begin{array}{c}\square(z i)-S(z i) \\
\square\end{array}$ \\
\hline 14 & 2 & 2 & -1.783 & 0.4625 & 0.04 & 0.1 & -0.06 & 0.06 \\
\hline 15 & 1 & 3 & -1.348 & 0.4099 & 0.09 & 0.15 & -0.06 & 0.06 \\
\hline 16 & 2 & 5 & -0.913 & 0.3186 & 0.18 & 0.25 & -0.07 & 0.07 \\
\hline 17 & 3 & 8 & -0.478 & 0.1808 & 0.32 & 0.4 & -0.08 & 0.08 \\
\hline 18 & 3 & 11 & -0.043 & 0.016 & 0.48 & 0.55 & -0.07 & 0.07 \\
\hline 19 & 3 & 14 & 0.391 & 0.1517 & 0.65 & 0.7 & -0.05 & 0.05 \\
\hline 20 & 3 & 17 & 0.826 & 0.2939 & 0.79 & 0.85 & -0.06 & 0.06 \\
\hline 21 & 2 & 19 & 1.261 & 0.3962 & 0.90 & 0.95 & -0.05 & 0.05 \\
\hline 22 & 1 & 20 & 1.696 & 0.4545 & 0.95 & 1 & -0.05 & 0.05 \\
\hline$\square$ & 20 & & & & & & & \\
\hline
\end{tabular}


Dari tabel 3. dapat diketahui bahwa Lo terbesar adalah 0.08. Ltabel-nya berdasarkan tabel Liliefors dengan perhitungan $n=20$ dan $\alpha=5 \%$, sehingga dapat diketahui nilai Ltabel adalah 0.19. oleh karena itu, dapat diketahui bahwa nilai Ltabel > Lo $(0.19>0.08)$ maka skor hasil belajar Biologi materi Ekosistem kelas eksperimen berdistribusi normal.

Uji Normalitas Kelas Kontrol

Hipotesis:

$H_{0} \quad=$ data berasal dari populasi yang berdistribusi normal.

$H_{l} \quad$ = data tidak berasal dari populasi yang berdistribusi normal.

Kriteria:

Terima $H_{l}$ jika Lo lebih kecil dari Ltabel.

Terima $H_{0}$ jika Lo lebih besar dari Ltabel.

Dari tabel distribusi normal skor hasil belajar kelas kontrol dapat diketahui nilai rataratanya adalah 15.8 dan simpangan bakunya adalah 2.6.

Tabel 4. Uji Normalitas Kelas Kontrol

\begin{tabular}{|c|c|c|c|c|c|c|c|c|}
\hline SKOR $(x i)$ & $f i$ & $f k$ & $z i$ & NILAI TABEL & $f(z i)$ & $S(z i)$ & $f(z i)-S(z i)$ & $|f(z i)-S(z i)|$ \\
\hline 11 & 2 & 2 & -1.846 & 0.4671 & 0.03 & 0.1 & -0.067 & 0.067 \\
\hline 12 & 1 & 3 & -1.462 & 0.4279 & 0.07 & 0.15 & -0.078 & 0.078 \\
\hline 13 & 2 & 5 & -1.077 & 0.3577 & 0.14 & 0.25 & -0.108 & 0.108 \\
\hline 14 & 1 & 6 & -0.692 & 0.2549 & 0.25 & 0.3 & -0.055 & 0.055 \\
\hline 15 & 2 & 8 & -0.308 & 0.1179 & 0.38 & 0.4 & -0.018 & 0.018 \\
\hline 16 & 3 & 11 & 0.077 & 0.0279 & 0.53 & 0.55 & -0.022 & 0.022 \\
\hline 17 & 1 & 12 & 0.462 & 0.1772 & 0.68 & 0.6 & 0.080 & 0.080 \\
\hline 18 & 5 & 17 & 0.846 & 0.2995 & 0.80 & 0.85 & -0.051 & 0.051 \\
\hline 19 & 3 & 20 & 1.231 & 0.3907 & 0.89 & 1 & -0.109 & 0.109 \\
\hline$\Sigma$ & 20 & & & & & & & \\
\hline
\end{tabular}

Dari tabel di atas dapat diketahui bahwa Lo terbesar adalah 0.109. Ltabelnya berdasarkan tabel Liliefors dengan perhitungan $n=20$ dan $\alpha=5 \%$, sehingga dapat diketahui nilai Ltabel adalah 0.19. oleh karena itu, dapat diketahui bahwa nilai Ltabel > Lo $(0.19>0.109)$ maka skor hasil belajar Biologi materi Ekosistem kelas kontrol berdistribusi normal.

Tabel 5. Uji Normalitas Skor Hasil Belajar Siswa

\begin{tabular}{|c|c|c|c|c|c|}
\hline Kelas & $n$ & $\alpha$ & Lo & Ltabel & KEPUTUSAN \\
\hline Eksperimen & 20 & $5 \%$ & 0.08 & 0.19 & \multirow{2}{*}{$\begin{array}{c}\text { Kedua kelas } \\
\text { berdistribusi } \\
\text { normal }\end{array}$} \\
\hline Kontrol & 20 & $5 \%$ & 0.109 & 0.19 & \\
\hline
\end{tabular}

Tabel 6. Uji Homogenitas Skor Hasil Belajar Siswa

\begin{tabular}{|c|c|c|c|c|c|}
\hline $\mathrm{K}$ & $\mathrm{Dk}$ & $\alpha$ & Fhitung & Ftabel & KESIMPULAN \\
\hline 2 & 19 & 0.05 & 1.13 & 2.165 & $\begin{array}{c}\text { Kedua kelas } \\
\text { homogen }\end{array}$ \\
\hline
\end{tabular}




\section{Pengujian Hipotesis Penelitian}

Hasil dari perhitungan jumlah skor hasil belajar siswa kelas X di kelompok eksperimen dan kontrol maka data tersebut dimasukkan dalam tabel di bawah ini.

Tabel 7. Data Skor untuk Uji Hipotesis

\begin{tabular}{|c|c|c|}
\hline \multirow{2}{*}{ KELOMPOK } & \multicolumn{2}{|c|}{ SKOR HASIL BELAJAR SISWA KELAS X } \\
\cline { 2 - 3 } & EKSPERIMEN & KONTROL \\
\hline$n$ & 20 & 20 \\
\hline $\bar{x}$ & 18.1 & 15.8 \\
\hline$S$ & 2.3 & 2.6 \\
\hline
\end{tabular}

$$
\begin{gathered}
S=\sqrt{\frac{\left(n_{1}-1\right) S_{1}^{2}+\left(n_{2}-1\right) S_{2}^{2}}{n_{1}+n_{2}-2}} \\
\text { Thitung }=\frac{\bar{x}_{A}-\bar{x}_{B}}{s \sqrt{\frac{1}{n_{A}}}}
\end{gathered}
$$

Jika harga Ttabel untuk taraf signifikan 0.05 dan $d k=n-1=20-1=19$, dari tabel distribusi-t adalah 2.093. Oleh karena itu, dapat diketahui bahwa nilai Thitung > Ttabel (4.647 > 2.093) maka dapat disimpulkan bahwa $H_{0}$ ditolak atau hasil pengujian signifikan yang berarti nilai rata-rata nilai hasil belajar untuk kelas eksperimen lebih tinggi dibandingkan dengan hasil belajar siswa untuk kelas kontrol. Hal ini menunjukkan bahwa adanya perbedaan yang signifikan atau nyata dari pemberian pengajaran dengan efektifitas metode pembelajaran resource based learning dengan metode diskusi terhadap hasil belajar Biologi materi ekosistem.

\section{Pembahasan}

Pada hasil penelitian dapat diketahui hasil belajar dari kelas eksperimen dengan skor rata-rata 18.1, median 18.2, modus 18.5, simpangan 2.3, dan Lo 0.08, sedangkan hasil belajar dari kelas kontrol dengan skor rata-rata 15.8, median 16.1, modus 17 , simpangan 2.6, dan Lo 0.109. Dari hasil perhitungan tersebut dapat diketahui bahwa skor rata-rata kelas ekperimen (metode resource based learning) lebih tinggi daripada kelas kontrol (metode diskusi) dengan selisih 2.3 dengan data masing-masing kelas berdistribusi normal dan dari hasil perhitungan uji homogenitas dapat diketahui Fhitung sebesar 1.13. Oleh karena itu, kedua data tersebut mempunyai varians yang homogen. Setelah diketahui dari hasil perhitung bahwa skor rata-rata kelas eksperimen lebih tinggi dibandingkan skor rata-rata kelas kontrol, diperkuat lagi dengan pengujian hipotesis menggunakan Uji-t yang diketahui hasilnya Thitung sebesar 4.647. Dari hasil tersebut dapat disimpulkan bahwa $H_{0}$ ditolak yang berarti hasil belajar dengan metode resource based learning lebih efektif dibandingkan hasil belajar dengan metode diskusi.

Dari hasil perolehan data dapat diketahui bahwa metode resource based learning mempunyai hasil belajar yang lebih tinggi dibandingkan metode diskusi karena metode resource based learning ini mempunyai kelebihan-kelebihan. Dalam pelaksanaannya, metode resource based learning mempunyai cara belajar yang bermacam-macam bentuk dan segi-seginya, sehingga dapat disesuaikan dengan kebutuhan dan suasana kelas, dapat berbentuk belajar kelompok ataupun individu. Metode ini tampaknya sebagai sesuatu yang terdiri atas berbagai komponen yang meliputi pengajaran langsung oleh guru, 
penggunaan buku panduan pelajaran, latihan-latihan formal, maupun kegiatan-kegiatan lainnya. Sumber belajar juga bisa didapati dari lingkungan sekolah seperti ruang kelas dan taman sekolah. Sumber lainnya juga bisa berasal dari koran, majalah, televisi, radio, internet, dan artikel, sehingga siswa menjadi lebih kreatif dan aktif untuk mendapatkan sumber belajar.

Lain halnya dengan metode diskusi, metode ini mempunyai hasil belajar yang lebih rendah dikarenakan kadang bisa terjadi adanya pandangan dari berbagai sudut bagi masalah yang dipecahkan, dalam diskusi menghendaki pembuktian logis, yang tidak terlepas dari fakta-fakta, tidak dapat dipakai pada kelompok besar, peserta mendapat informasi yang terbatas, mungkin dikuasai orang-orang yang suka berbicara, dan biasanya orang menghendaki pendekatan yang lebih formal.

Dengan demikian, dapat disimpulkan bahwa terdapat perbedaan yang cukup besar antara siswa dengan hasil belajar yang baik menggunakan metode resource based learning dengan hasil belajar yang menggunakan metode diskusi dalam matapelajaran Biologi materi Ekosistem.

\section{PENUTUP}

\section{Kesimpulan}

Dengan demikian hasil penelitian menyimpulkan bahwa hasil belajar Biologi siswa kelas X materi Ekosistem semester 2 tahun ajaran 2011/2012 MA Al-Khairiyah yang diajarkan dengan metode diskusi mempunyai nilai rata-rata paling rendah, yaitu 15.8, sedangkan, nilai rata-rata hasil belajar yang menggunakan metode resource based learning lebih tinggi daripada hasil belajar dengan metode diskusi, yaitu 18.1, sehingga terdapat perbedaan rata-rata skor dengan selisih 2.3. Berdasarkan dari Uji hipotesis dengan Uji-t dapat diketahui hasilnya bahwa $H_{0}$ ditolak atau hasil pengujian signifikan yang berarti terdapat perbedaan antara efektifitas metode resource based learning dan metode diskusi pada hasil belajar Biologi materi Ekosistem kelas X MA Al-Khairiyah.

\section{Implikasi}

Dari hasil penemuan ini, maka dapat direkomendasikan bagi sekolah agar guru dapat menerapkan metode resource based learning dalam memberikan materi kepada siswa dan kepala sekolah dapat menyediakan fasilitas-fasilitas yang mendukung untuk pelaksanaan metode ini serta siswa harus lebih meningkatkan kemauan dan kreativitasnya dalam mencari sumber belajar dan meningkatkan hasil belajarnya. Bagi siswa dan sekolah, hasil tersebut dapat digunakan sebagai bahan introspeksi bahwa hasil belajar dapat ditingkatkan dengan guru menerapkan variasi dalam metode pembelajaran agar ada daya tarik siswa untuk memahami pelajaran dengan baik, sedangkan secara keseluruhan dapat digunakan untuk perbaikan mutu pendidikan di MA Al-Khairiyah Jakarta.

\section{Saran}

Berdasarkan kesimpulan dan implikasi dari penelitian ini, saran-saran yang diajukan sebagai berikut.

1. Bagi Guru, perbedaan hasil belajar siswa hendaknya menjadi bahan kajian dan perhatian dalam rangka meningkatkan kualitas hasil belajar siswa terutama bagi siswa yang akan melanjutkan ke jenjang yang lebih tinggi. Dalam penyampaian materi hendaknya guru memvariasikan dalam penggunaan metode pembelajaran dan suasana kelas sehingga siswa lebih bergairah dan termotivasi dalam belajar.

2. Bagi Siswa, selama guru menyampaikan materi pelajaran hendaknya siswa terfokus pada guru dan tidak membuat suasana kelas menjadi tidak nyaman, seperti membuat 
suara gaduh, keluar masuk kelas, ataupun hal lainnya, hal tersebut sangat mengganggu siswa lainnya serta menghambat guru dalam memberikan materi pelajaran di kelas.

3. Bagi Instansi Terkait, penggunaan metode dan sarana pembelajaran yang bervariasi sudah selayaknya menjadi prioritas, guna meningkatkan kompetensi dan profesionalisme guru melalui kegiatan pelatihan dan pembinaan yang berkesinambungan.

4. Bagi Calon Peneliti, peneliti menyarankan untuk meneliti lebih lanjut mengenai faktor-faktor penyebab rendahnya hasil belajar siswa dikarenakan penggunaan metode pembelajaran yang monoton dan menjenuhkan siswa.

\section{DAFTAR PUSTAKA}

Amien, Muhammad. 1983. Peranan Kreativitas dalam Pendidikan. Jakarta: Departemen Pendidikan dan Kebudayaan.

Amin, Mohamad. 2009. Biologi SMA/MA Kelas X. Jakarta: PT. Bumi Aksara.

Arikunto, Suharsimi. 1997. Prosedur Penelitian Suatu Pendekatan Praktek. Yogyakarta: Rineka Cipta.

Arikunto, Suharsimi. 2010. Prosedur Penelitian Suatu Pendekatan Praktek. Yogyakarta: Rineka Cipta.

Bahri Djamarah, Syaiful. 1997. Guru dan Anak Didik dalam Interaksi Edukatif. Jakarta: Rineka Cipta.

Cahyanta, Hari. 2011. Pengertian Hasil Belajar Biologi. Dalam http://dasarteori.blogspot.com/ 2011/ 08/ pengertian- hasil- belajar- biologi.html. Di Akses pada Tanggal 23 Mei 2012.

Degeng dan Nyoman Sudana. 1998. Ilmu Pengajaran Taksonomi Variabel. Jakarta. Departemen P\&K Dirjen Dikti. Proyek Pengembangan Lembaga Pendidikan Tenaga Pendidikan.

Dimyati dan Mudjiono. 2009. Belajar dan Pembelajaran. Jakarta: Rineka Cipta.

Ferdinand, Fictor dan Moekti Ariebowo. 2009. Praktis Belajar Biologi 1. Jakarta: Pusat Perbukuan Departemen Pendidikan Nasional.

Hamalik, Oemar. 2005. Proses Belajar Mengajar. Jakarta: Bumi Aksara.

Hasanah, Siti dan Suparman. 2005. Belajar dan Pembelajaran. Jakarta: Universitas Indraprasta PGRI.

Hasibuan dan Moedjiono. 2010. Proses Belajar Mengajar. Bandung: Rosda.

Ihsan, Fuad. 1996. Dasar-Dasar Kependidikan. Jakarta: Rineka Cipta.

Indriyanto.2006. Ekologi Hutan. Jakarta: Bumi Aksara.

James, Popham W., dan Eva L. Baker. 2008. Teknik Mengajar secara Sistematis. Jakarta: Rineka Cipta.

Majid, Abdul. 2009. Perencanaan Pembelajaran. Bandung: Rosda.

Margono. 2009. Metodologi Penelitian Pendidikan. Jakarta: Rineka Cipta.

Miarso, Yusufhadi. 2004. Menyemai Benih Teknologi Pendidikan. Jakarta: Prenada Media.

Munadi, Yudhi dan Farida Hamid. 2011. Pembelajaran Aktif, Inovatif, Kreatif, Efektif, dan Menyenangkan. Jakarta: UIN Syarif Hidayatullah.

Nasution. 2009. Berbagai Pendekatan dalam Proses Belajar dan Mengajar. Jakarta: Bumi Aksara.

Novel, Sinta Sasika. 2010. Rangkuman Biologi SMA. Jakarta: Transmedia.

Odum, E. HLM. 1993. Dasar-Dasar Ekologi. Terjemahan oleh Tjahjono Samingan dari buku Fundamentals of Ecology. Yogyakarta: Gadjah Mada University Press.

Priadi, Arif. 2009. Biology 1 for Senior High School. Jakarta: Yudhistira. 
Riyadi, Pawit. 2011. Hakikat Pembelajaran Biologi. Dalam http://pawitriyadi87.blogspot.com/2011/12/hakikat-pembelajaran biologi. html. Di Akses pada Tanggal 23 Mei 2012.

Roestiyah. 2008. Strategi Belajar Mengajar. Jakarta: Rineka Cipta.

Sadiman, Arief, Anung Haryono Rahardjo dan Hardjito. 1986. Media Pendidikan, Pengertian, Pengembangan, dan Pemanfaatannya. Jakarta: Rajawali.

Safari. 2008. Analisis Butir Soal. Jakarta: Asosiasi Pengawas Sekolah Indonesia (APSI).

Sanjaya, Wina. 2008. Strategi Pembelajaran. Jakarta: Kencana.

Setiadi, Y. 1983. Pengertian Dasar tentang Konsep Ekosistem. Bogor: Fakultas Kehutanan Institut Pertanian Bogor.

Slameto. 1998. Belajar dan Faktor-Faktor yang Mempengaruhinya. Jakarta: Bina Aksara.

Subana. 2005. Dasar-Dasar Penelitian Ilmiah. Bandung: Pustaka Setia.

Soemarwoto, E. 1983. Ekologi Lingkungan Hidup dan Pembangunan. Jakarta: Penerbit Djambatan.

Sudijono, Anas. 2011. Pengantar Evaluasi Pendidikan. Jakarta: Rajagrafindo Persada.

Sukmadinata, Nana Syaodih. 2009. Landasan Psikologi Proses Pendidikan. Bandung: Rosda.

Supardi. 2012. Aplikasi Statistika dalam Penelitian. Jakarta: Ufuk Press.

Suryosubroto. 2009. Proses Belajar Mengajar di Sekolah. Jakarta: Rineka Cipta.

Susilo, Herawati. 2004. Materi Pokok Kapita Selekta Pembelajaran Biologi. Jakarta: Universitas Terbuka.

Syamsuri, Istamar.2004. Biologi SMA X. Jakarta: Erlangga.

Widarti, Sri. 2006. Strategi Meningkatkan Kreatifitas Mendesain Busana Melalui Penerapan Pendekatan Pembelajaran Resource Based Learning. Yogyakarta: Majalah Ilmiah Pembelajaran.

Widayati, Sri. 2009. Biologi SMA X. Jakarta: Pusat Perbukuan Departemen Pendidikan Nasional.

Winkel, W.S. 1996. Psikologi Pengajaran. Jakarta: Grasindo. 